\title{
Integration of Knowledge Management with Adaptive Performance: An Exploration Role of Organizational Learning in Hindustan Aeronautics Ltd (HAL)
}

\author{
Venkata Naga Siva Kumar Challa*, Parimi Padmalatha, Burra Vamsi Krishna \\ Department of Management Studies, Ramachandra College of Engineering, Vatluru, India \\ Email address: \\ challasivakumar2000@gmail.com(V. N. S. K. Challa), padmalatha35@gmail.com (P. Padmalatha), vamsibu@gmail.com (B. V. Krishna) \\ ${ }^{*}$ Corresponding author
}

To cite this article:

Venkata Naga Siva Kumar Challa, Parimi Padmalatha, Burra Vamsi Krishna. Integration of Knowledge Management with Adaptive Performance: An Exploration Role of Organizational Learning in Hindustan Aeronautics Ltd (HAL). Journal of Business and Economic Development. Vol. 6, No. 2, 2021, pp. 97-103. doi: 10.11648/j.jbed.20210602.15

Received: April 22, 2021; Accepted: May 13, 2021; Published: May 21, 2021

\begin{abstract}
The Business scenario today is changing rapidly the business is totally depending upon the customer needs. The days are gone where the customers used to buy the products which are manufactured as per the manufacturer choice. Now the market is totally depending upon the customer needs and with the rapid emerging of technology the business scenario is changing at the speed of a blink. Increasingly firms find themselves, either by design or circumstances, operating in business environment, fraught with unprecedented, unparalleled, unrelenting and largely unpredictable changes. As a result, knowledge management is rapidly being seen as a critical source of sustainable competitive advantage. Maintaining a competitive edge is a constant struggle for both businesses. In the changing environment to retain the competitive advantage, adaptive performance is the means to meet unexpected or changing demands of business scenario. The present study focuses on whether Knowledge Management promotes the adaptive performance and explores the mediating role of Organizational Learning.
\end{abstract}

Keywords: Knowledge Management, Adaptive Performance, Organizational Learning, Competitive Advantage

\section{Introduction}

We have witnessed the growth of human resource discipline from welfare role to a strategic business partner role. The Human Resource Management has grown in many folds since the date of evolution. Several factors have converged over the last decade to influence the position, importance, and practices of human resource management in organizations [2] These dynamics work on a variety of levels which present significant problems and difficulties for organizational management. With the levels of employment of the most educated workforce increasing, changing demographics of workforce, changing technologies, Human Resource Management has now become the key role for the success of any business.

Change is everywhere and all the time. Along with growth Human Resource management is facing many challenges because of its dynamic nature. There is Quest for improvement of Productivity through Human Resources. The
Potentiality of Human Resources is being utilized for various benefits of the organization. [1] Many HRD interventions from the Employee Selection to Employee separation, has been evolved to make the Organization more profitable. In a world of increased Volatility, Uncertainty, Complexity and Ambiguity (VUCA) Human Resource issues matter more than ever [3] The rapid changes in the business scenario and growth of competition in the market is posing various challenges to Human Resource management. Human Resource management which has started as business function has assumed the role of Business partner and now it is emerging as the strategic business partner. This Strategic Human Resource Management is involving in shaping up the Human Resources to contribute to the business success and in integration of human capital to the business strategy.

\subsection{Knowledge as Competitive Advantage}

In an economy where the only certainty is insecurity, awareness is the only form of sustainable competitive 
advantage [4] The critical role of intelligence as a means of strategic competitive advantage [5] For the last two decades, has been slowly increasing. This expansion has been accompanied by an acknowledgment that the opportunity to learn better than rivals could be the only source of competitive advantage" [6] As the era of agricultural economy, industrial economy has come to an end and new era of knowledge is emerging the knowledge is playing a vital role in building up an organization. Civilization progressed from the agrarian and the industrial to the information eras; we are now transitioning from the information to the intelligence eras. In the knowledge age, we make smarter choices based on wisdom-infused knowledge rather than purely on information [7]. As the speed of transition accelerates, uncertainty increases, reducing the useful life of the majority of competitive edge goods.

The term "knowledge" refers to "understanding acquired by practice." It is a person's "know-how" or experience with how to do a specialized activity that allows them to do so. Additionally, it may be a set of statistics, procedural codes, or heuristics [8]. Knowledge is a set of data, priori rules, and heuristics. A fact is an assertion that contains at least one element of reality regarding a topic or jurisdiction. A preduodenal law is one that enumerates a series of relationships with respect to the primary. A heuristic is a rule of thumb developed over time.

\subsection{Definitions of Knowledge}

It is understood that knowledge is justified belief, an understanding gained through practice. Knowledge is the possession of information that allows an individual to conduct a specialized activity. Individuals benefit from knowledge because it enables them to behave more efficiently and to forecast the outcomes of their actions. Knowledge is capacity for effective action [9].

According to [10], writers such as Davenport and Prusak (1998), Nonaka (1991), Polanyi (1997), and Nickols (2000) have made significant contributions to our interpretation of science. Knowledge is a complex amalgamation of framed perspectives, beliefs, qualitative data, and expert perspective that serves as a basis for interpreting and applying new experiences and facts. It originates and is implemented in the minds of all who are knowledgeable. It frequently gets rooted in organizations' routines, systems, activities, and conventions, not only in records or libraries.

Awareness is described in corporate and organizational contexts as: Know-how: a combination of intuition, understanding, experience, and foresight. A unique combination of intelligence and intuition that allows someone to "understand how" to do things in order to decide the most suitable course of action. Thus, knowledge is primarily derived from the mutual understanding of an organization's workers [11].

Knowledge Management Concept

The concept of Knowledge Management can be understood using a variety of perspectives. The few different perspectives to consider, all of which accurately portray Knowledge Management:

1) Knowledge Management maximizes human and organizational assets by optimizing the use of wisdominfused knowledge for the purpose of increasing efficiency, creativity and successful execution of an organization's mission.

2) Knowledge Management enhances the way that an organization can intelligently leverage human capital and intellectual assets.

3) Knowledge management entails the collection, storage, retrieval, creation, using, and sharing of institutional knowledge.

4) Knowledge Management also involves managing knowledge and knowledge processes.

\subsection{Organizational Learning}

Organizational learning is an ongoing mechanism that improves an organization's mutual capacity for accepting, making sense of, and responding to internal and external transition. Organizational preparation is more than the amount of workers' knowledge. It entails the formal synthesis and collaborative understanding of new knowledge, as well as risk-taking and exploration. The method of developing, retaining, and transmitting information inside an organization is referred to as organizational learning. Organizational learning is concerned with capturing information acquired from practice and then rendering it accessible to others as it is applicable to their jobs. Organizational development encompasses all human and group learning within an organization, as well as everything in between these two extremes. [12]. The organizational learning will enable the Individual to adapt to the changing environment.

\subsection{Adaptive Performance}

Work organizations and their workers face significant environmental challenges that necessitate adaptive reform. Numerous factors also led to this need for extreme adaptation. The transition from production to knowledgebased practice has sparked change. The recent focus on information work necessitates that workers maintain their talents and experience on a continuous basis. However, a more profound shift occurs as a result of the reality that although specialization is usually necessary to be proficient in one's profession, certain jobs need the collective skills of many individuals. This needs not only adaptability in terms of collaborating with individuals with varying levels of experience, but also adaptability in terms of collaborating with individuals with varying experiences and desires [13].

Economic constraints have resulted in strong corporate rivalry over the last 25 years. This rivalry forced executive leaders to make a series of organizational-level adjustments, which in turn necessitated individual employee adjustments. Businesses also buy, combine, or create partnerships with other businesses in order to use competitive firm-specific capital. These concerns, along with the constant advances in 
technology, have prompted workers to follow a "continuous development" mindset and see capability training as a lifelong endeavor - a necessary adaptation in the modern era. Changes in the broader world in which businesses operate often contribute to organizational rivalry. Today's business environment is increasingly global, and rivalry through come from across oceans as well as across the street. Globalization's meteoric growth and companies' ongoing penetration into new markets also necessitated adaptation of citizens with diverse backgrounds and languages [14].

\section{Significance and Need for the Study}

The thesis is unusual in that it employs observational assessments to determine the effect of knowledge management on adaptive efficiency. Additionally, the research investigates the mediating effect of Organizational Learning in the process of Knowledge Management's impact on Adaptive Performance. This study focuses on the impact of knowledge management on adaptive performance at Hindustan Aeronautics Limited, India's premier aerospace company. By having a better understanding of the interdependence of information management and adaptive performance, Hindustan Aeronautics Limited will be able to deploy tactics and assess the best way to leverage their capital more effectively than in the past. Additionally, an appreciation of this interdependence will aid in the development of a unified system through which the principles could be implemented to improve resilience in the new age of constant transition. Hindustan Aeronautics Limited can profit from this study by gaining knowledge about how Knowledge Management, Organizational Learning influences the adaptive performance to face the future challenges and projects. This study may also stimulate the future studies on Adaptive Performance in various domains.

The study's scope is to examine the processes, policies, and techniques of knowledge management in HAL and their effect on adaptive performance, as well as the mediating function of organizational learning.

The study shows broad analysis of the demographic profile towards the various factors affecting Knowledge Management. The study covered varied age groups possessing different educational backgrounds in the junior, middle and senior managerial levels in HAL division at Sunabeda, Division, Koraput, Odisha.

\section{Research Questions}

1) Does Knowledge Management promote Adaptive Performance in the Organization?

2) To what extent does Knowledge Management have a positive influence on Adaptive Performance?

3) Does Organizational learning mediate the relationship between Knowledge Management and adaptive Performance?

\subsection{Objectives of the Study}

1) To examine the organizational Learning Strategies in HAL.

2) To study the policies on Knowledge Acquisition, Knowledge Transfer and Knowledge Application process in HAL.

3) To examine the process of Individual Learning, Group learning and organizational Learning in HAL.

4) To identify the interdependency of Knowledge Management on Adaptive Performance and explore the mediating role of organizational Learning.

5) To assess the impact of socio-economic variables on the parameters of the study.

6) To suggest appropriate measures to HAL on better strategies to knowledge management in the organization.

\subsection{Research Design}

The present study deals with the impact of Knowledge Management on Adaptive Performance exploring the mediating role of Organizational Learning with reference to HAL, Sunabeda. The present study is a descriptive study encompassing the parameters of knowledge management and the impact of socio-economic variables on the parameters also studying about the impact of knowledge management on adaptive performance and the mediating role of Organizational Learning.

From the records of Hindustan Aeronautics Limited, Sunabeda Division, Koraput, Odisha it is observed that there are 1856 employees in management, executive and staff category, 542 employees in special scale and 3184 are Workmen in the shop floor. Since the study on Knowledge Management is more appropriate special employees and managerial employee's cadre are considered, workmen are excluded. Therefore, the universe of the study was 2398 employees, of which 25 percent are selected and identified as sample for the study through Systematic Random Sampling Method this gives 600 employees. For this sampling frame of the population was considered and every fourth individual was selected from the random start.

The questionnaire which was prepared after, pre- tested and improved is circulated among all these selected sample personnel. It was found that 28 questionnaires were not duly signed or not in proper order, hence they were ignored. Ultimately, the data collected from the remaining 572 employees are considered and utilized for the study.

The items of the research instrument consist of a wellstructured questionnaire with 8 items covering the socioeconomic parameters and 65 items encompassing the three key parameters namely Knowledge management, Learning and Adaptive performance which were further divided into 11 sub parameters i.e., three sub parameters namely Knowledge acquisition, knowledge transfer, knowledge application under the category of key parameter Knowledge Management developed by Fillings. [15] was considered. In addition, three sub parameters namely Individual learning, group learning and organizational learning under the category 
of key parameter Organizational Learning developed by Watkins [16] and five sub parameters namely reactivity in the case of emergencies, managing work stress, problem solving creativity, training and learning effort and interpersonal adaptability under the key parameter of Adaptive performance developed by Voirin. A. C. and Roussel. [17] for which Likert's five-point scaling technique has been designed. The researcher has conducted a pilot study and reliability test of the data to obtain accuracy of the results of the study.

The respective scores are obtained from different respondents of the study. Basing on these score values the individual average scores are calculated from each respondent for every statement. The average score value is calculated by summation of each respondent score divided by total number of questions present in each parameter. The value so obtained is considered as individual scores for that parameter.

To test the dependency of different socio-economic and demographic conditions on the level of knowledge management among the sample group, cross tabulations are made and chi-square tests for testing the independence of attributes are performed. To know the average scores provided by the employees on different parameters of knowledge management whether significantly same or not, one way analysis of variance was carried out. In case of situation where the average scores of these 11 parameters are significantly different, a further analysis using t-test for testing the significant difference between average scores provided by the employees towards different parameters of knowledge management are made for different possible combination of the pairs obtained from eleven different parameters of knowledge management. Further to test the dependency between knowledge management and adaptive performance and the impact of knowledge management on adaptive performance while exploring the mediating role of organizational learning regression equation was carried on.

The level of knowledge management, organizational learning and adaptive performance has been calculated with a statistical tool and statistics like F-test, mean, standard deviation, t-test, ANOVA and regression.

\section{Results and Discussion}

Assessing whether there exists any significant difference among the average scores of different parameters:

To know whether there exits any significant difference among the means of the average scores of different parameters under study, the Analysis of Variance techniques for testing the significant difference among the average scores of parameters, were applied and the ANOVA table was presented in Table 1.

Table 1. ANOVA Table for testing the significance of differences among different parameters.

\begin{tabular}{llllll}
\hline Sources of Variation & SS & df & MS & F & p-value \\
\hline Between Groups & 64.17967 & 10 & 6.417967 & 25.24523 & $1.68 \mathrm{E}-47$ \\
Within Groups & 1596.787 & 6281 & 0.254225 & & \\
Total & 1660.967 & 6291 & & \\
\hline
\end{tabular}

From Table 1 it can be inferred that there is a significant difference among the means of the average scores of parameters as $\mathrm{p}$ value is $1.68 \mathrm{E}-47$. That is, means of all the eleven parameters differing significantly from each other.
Hence, further analysis is required to infer which pair of paramours differ, paired t test was applied for all the possible 55 pairs and presented in Table 2 and Table 3

Table 2. Showing t test values between average scores of different possible parameters.

\begin{tabular}{|c|c|c|c|c|c|}
\hline Average scores of different pairs of parameters & Mean & S. D & $\mathbf{t}$ & df & p value \\
\hline Knowledge Acquisition - Knowledge Transfer & .27218 & .69879 & 9.315 & 571 & .000 \\
\hline Knowledge Acquisition - Knowledge Application & .09421 & .65782 & 3.425 & 571 & .001 \\
\hline Knowledge Acquisition - Individual Learning & .31763 & .89518 & 8.486 & 571 & .000 \\
\hline Knowledge Acquisition - Group Learning & .27468 & .82327 & 7.980 & 571 & .000 \\
\hline Knowledge Acquisition - Organizational Learning & .23879 & .68683 & 8.315 & 571 & .000 \\
\hline Knowledge Acquisition - Reactivity in the case of emergencies & -.1507 & .88656 & -4.066 & 571 & .000 \\
\hline Knowledge Acquisition - Managing Stress & -.2657 & .93880 & -6.769 & 571 & .000 \\
\hline Knowledge Acquisition - training and learning effort & -.0974 & .77098 & -3.022 & 571 & .003 \\
\hline Knowledge Acquisition - Inter personal adoptability & -.2774 & .91364 & -7.263 & 571 & .000 \\
\hline Knowledge Transfer - Knowledge Application & -.1779 & .73597 & -5.783 & 571 & .000 \\
\hline Knowledge Transfer - Individual Learning & .04545 & .97738 & 1.112 & 571 & .266 \\
\hline Knowledge Transfer - Group Learning & .00251 & .83096 & .072 & 571 & .943 \\
\hline Knowledge Transfer - Organizational Learning & -.0334 & .71181 & -1.122 & 571 & .262 \\
\hline Knowledge Transfer - Reactivity in the case of emergencies & -.4229 & .95692 & -10.57 & 571 & .000 \\
\hline Knowledge Transfer - Managing Stress & -.5379 & .98630 & -13.04 & 571 & .000 \\
\hline Knowledge Transfer - training and learning effort & -.3696 & .83654 & -10.57 & 571 & .000 \\
\hline Knowledge Transfer - Inter personal adoptability & -.5497 & .98680 & -13.3 & 571 & .000 \\
\hline Knowledge Application - Individual Learning & .22343 & .82199 & 6.501 & 571 & .000 \\
\hline Knowledge Application - Group Learning & .18048 & .84357 & 5.117 & 571 & .000 \\
\hline
\end{tabular}




\begin{tabular}{|c|c|c|c|c|c|}
\hline Average scores of different pairs of parameters & Mean & S. D & $\mathbf{t}$ & df & p value \\
\hline Knowledge Application - Organizational Learning & .14458 & .75028 & 4.609 & 571 & .000 \\
\hline Knowledge Application - Reactivity in the case of emergencies & -.2449 & .86297 & -6.79 & 571 & .000 \\
\hline Knowledge Application - Managing Stress & -.3599 & .88526 & -9.72 & 571 & .000 \\
\hline Knowledge Application - Problem solving creativity & -.2231 & .82912 & -6.44 & 571 & .000 \\
\hline Knowledge Application - training and learning effort & -.1916 & .80931 & -5.66 & 571 & .000 \\
\hline Knowledge Application - Inter personal adoptability & -.3717 & .93342 & -9.52 & 571 & .000 \\
\hline Individual Learning - Group Learning & -.043 & .73154 & -1.40 & 571 & .161 \\
\hline Individual Learning - Reactivity in the case of emergencies & -.4684 & 1.11695 & -10.0 & 571 & .000 \\
\hline Individual Learning - Managing Stress & -.5833 & 1.16288 & -11.1 & 571 & .000 \\
\hline Individual Learning - Problem solving creativity & -.4465 & 1.09093 & -9.79 & 571 & .000 \\
\hline Individual Learning - training and learning effort & -.415 & 1.1041 & -8.99 & 571 & .000 \\
\hline Individual Learning - Inter personal adoptability & -.5951 & 1.25060 & -11.4 & 571 & .000 \\
\hline
\end{tabular}

Table 3. Showing t test values between average scores of different possible parameters.

\begin{tabular}{|c|c|c|c|c|c|}
\hline Average scores of different pairs of Parameters & Mean & S. D & $\mathbf{t}$ & df & p value \\
\hline Group Learning - Organizational Learning & -.036 & .57931 & -1.48 & 571 & .139 \\
\hline Group Learning - Reactivity in the case of emergencies & -.425 & 1.02344 & -9.94 & 571 & .000 \\
\hline Group Learning - Managing Stress & -.5404 & 1.02963 & -12.6 & 571 & .000 \\
\hline Group Learning - Problem solving creativity & -.4036 & 1.02936 & -9.38 & 571 & .000 \\
\hline Group Learning - training and learning effort & -.3721 & .97785 & -9.10 & 571 & .000 \\
\hline Group Learning - Inter personal adoptability & -.5522 & 1.14384 & -11.6 & 571 & .000 \\
\hline Organizational Learning - Reactivity in the case of emergencies & -.3895 & .91759 & -10.2 & 571 & .000 \\
\hline Organizational Learning - Problem solving creativity & -.3676 & .94833 & -9.27 & 571 & .000 \\
\hline Organizational Learning - training and learning effort & -.3362 & .90167 & -8.92 & 571 & .000 \\
\hline Reactivity in the case of emergencies - Problem solving creativity & .02185 & .81602 & .640 & 571 & .522 \\
\hline Reactivity in the case of emergencies - training and learning effort & .05332 & .85790 & 1.487 & 571 & .138 \\
\hline Reactivity in the case of emergencies - Inter personal adoptability & -.1268 & .76374 & -3.969 & 571 & .000 \\
\hline Managing Stress - Problem solving creativity & .1368 & .76521 & 4.277 & 571 & .000 \\
\hline Managing Stress - training and learning effort & .1683 & .92271 & 4.362 & 571 & .000 \\
\hline Problem solving creativity - Inter personal adoptability & -.1486 & .87620 & -4.056 & 571 & .000 \\
\hline training and learning effort - Inter personal adoptability & -.1801 & .79864 & -5.392 & 571 & .000 \\
\hline
\end{tabular}

From Tables 1 and 2 it can be inferred that there is no significant difference between the average scores of Knowledge Transfer and Individual learning, Knowledge Transfer and Group learning, Knowledge Transfer and organizational learning, Individual learning and Group learning, Group learning and organizational learning, Reactivity in the case of emergencies and Problem solving creativity, Reactivity in the case of emergencies and training and learning effort, Managing stress and Inter personal adoptability \& Problem solving creativity and training and learning effort whereas, in all other combinations of pairs, there exists a significant difference.

That is, the opinion of the respondents on knowledge acquisition and knowledge application differs from all other parameters. Knowledge transfer differs from all other parameters except in Individual learning, Group learning and organizational learning. That is, learning in all forms are associated with knowledge transfer. Individual learning differs from all other except with knowledge transfer and group learning. Group learning is different is different is different from all other parameters except with knowledge transfer, individual learning and organizational learning. Organizational learning is different from all other parameters except knowledge transfer, individual learning and group learning. Reactivity in case of emergencies is different from all other parameters except in problem solving creativity and training and learning effort. Managing stress is different in all other parameters except with interpersonal adoptability. Problem solving creativity is different in all other parameters except with training and learning effort. Interpersonal adoptability is different in all other parameters except with managing stress.

Assessing the impact of knowledge Management, Organizational learning, Age and experience on Adaptive Performance

There are 11 HR practices under which different statement were identified and basing on the responses / codes against each statement average scores were obtained for each HR practice. These HR practices were further grouped in to three broad categories namely Knowledge Management, Organizational Learning and Adaptive Performance. The average score for the Knowledge Management was obtained as average of the average scores previously obtained for Knowledge Acquisition, Knowledge Transfer and Knowledge Application. The average score for the Organizational Learning was obtained as average of the average scores previously obtained for Individual Learning, Group learning and Organizational Learning. The average score for the Adaptive Performance was obtained as average of the average scores previously obtained for Reactivity in 
the face of Emergencies, managing work Stress, Solving Problem creativity, Training and Learning effort and Interpersonal adoptability.

Using the average scores of the Knowledge Management, Organizational Learning and Adaptive Performance just obtained, to now the impact of knowledge Management, Organizational learning, Age and experience on Adaptive Performance multiple regression were carried out for different combinations of the independent variables and presented in table 4 The $p$ values which give the status of significance of the regression coefficients were presented in the parenthesis under the regression coefficients. Further to know the relation between the Knowledge Management and organizational learning regression analysis between Organizational learning on Knowledge Management were made and presented in Table 4 .

Table 4. Regression Models of Age, Experience, Knowledge management and Organizational Learning on Adaptive performance.

\begin{tabular}{|c|c|c|c|c|c|c|c|c|}
\hline \multirow{2}{*}{$\begin{array}{l}\text { Modal } \\
\text { No }\end{array}$} & \multirow[b]{2}{*}{ Dependent Variable } & \multirow[b]{2}{*}{ Constant } & \multicolumn{4}{|c|}{ Coefficients of independent variables } & \multirow[b]{2}{*}{$\mathbf{R}^{2}$} & \multirow{2}{*}{$\begin{array}{l}\text { Adjusted } \\
\mathbf{R}^{2}\end{array}$} \\
\hline & & & $\begin{array}{l}\text { Knowledge } \\
\text { management }\end{array}$ & $\begin{array}{l}\text { Organizational } \\
\text { learning }\end{array}$ & Age & Experience & & \\
\hline 1 & Adaptive Performance & $.462(.000)$ & $.694(.000)$ & - & - & - & .488 & .487 \\
\hline 2 & Adaptive Performance & $.655(.000)$ & - & $.454(.000)$ & - & - & .249 & .248 \\
\hline 3 & Adaptive Performance & $.641(.000)$ & - & - & $.066(.000)$ & - & .004 & .003 \\
\hline 4 & Adaptive Performance & $.603(.000)$ & - & - & - & $.694(.024)$ & .009 & .007 \\
\hline 5 & Adaptive Performance & $.459(.000)$ & $.731(.000)$ & $.045(.273)$ & - & - & .489 & .487 \\
\hline 7 & Adaptive Performance & $.329(.000)$ & $.693(.000)$ & - & $.050(.095)$ & - & .490 & .489 \\
\hline 8 & Adaptive Performance & $.559(.000)$ & - & $.452(.000)$ & $.037(.379)$ & - & .250 & .248 \\
\hline 9 & Adaptive Performance & $.463(.000)$ & - & $.452(.000)$ & - & $.084(.019)$ & .256 & .254 \\
\hline 10 & Adaptive Performance & $.236(.000)$ & $.691(.000)$ & - & $.037(.231)$ & $.057(.061)$ & .494 & .491 \\
\hline 11 & Adaptive Performance & $.426(.000)$ & - & $.452(.000)$ & $.018(.638)$ & $.080(.029)$ & .257 & 253 \\
\hline 12 & Adaptive Performance & $.320(.000)$ & $.733(.000)$ & $.049(.000)$ & $.053(.081)$ & - & .492 & .481 \\
\hline 13 & Adaptive Performance & $.313(.000)$ & $.727(.000)$ & $.043(.000)$ & - & $.065(.028)$ & .493 & .491 \\
\hline 14 & Adaptive Performance & $.229(.000)$ & $.729(.000)$ & $.047(.251)$ & $.039(.202)$ & $.056(.066)$ & .495 & .491 \\
\hline
\end{tabular}

Table 5. Regression Model of Organizational Learning on Knowledge management.

\begin{tabular}{|c|c|c|c|c|c|c|c|}
\hline \multirow{2}{*}{ Modal no } & \multirow{2}{*}{ Dependent variable } & \multirow{2}{*}{ Constant } & \multicolumn{3}{|c|}{ Coefficients of independent variables } & \multirow{2}{*}{$\mathbf{R}^{2}$} & \multirow{2}{*}{ Adjusted $\mathbf{R}^{2}$} \\
\hline & & & Organizational learning & Age & Experience & & \\
\hline 1 & Knowledge management & $0.267(.000)$ & $.687(.000)$ & & & 0.556 & 0.556 \\
\hline
\end{tabular}

From Table 4 it can be observed that there are 14 regression models in which Adaptive Performance is dependent variable and independent variables are different combinations of Knowledge Management, Organizational Learning, Age and Experience. Further from Table 5, Model 14, it can be inferred that the variables Knowledge Management, Organizational Learning, Age and Experience together is explaining 49.5 percent of variation in Adaptive Performance $\left(\mathrm{R}^{2}=0.495\right.$ and Adjusted $\left.\mathrm{R}^{2}=0.491\right)$.

After removing the Independent Variables Organizational Learning from the model gives the model 13 and from that model it can be observed that, the value of the $R^{2}=0.492$ and Adjusted $\mathrm{R}^{2}=0.491$ for that model.

After removing the Independent Variables Organizational
Learning and Age from the model gives the model 6 and for that model it can be observed that the value of the $R^{2}=0.492$ and Adjusted $\mathrm{R}^{2}=0.491$ for that model. This clearly shows that Organizational Learning and Age are not making any significant impact on Adaptive performance. If we remove the variable experience also from the model, there will be only one independent variable namely Knowledge Management and, in that case, $\mathrm{R}^{2}=0.488$ and Adjusted $\mathrm{R}^{2}=0.487$. This shows a small impact of experience is existing on Adaptive Performance. So, the model 6 can be taken as appropriate model in explaining the dependent variable Adaptive Performance in which Knowledge Management and experience are independent variables. And the model is as follows.

\section{Adaptive Performance $=0.314+0.692($ Knowledge Management $)+0.066$ (Experience)}

From Table 5, it can be inferred that the variation in Organizational Learning is explaining 56 percent of the variation in Knowledge Management since $\mathrm{R}^{2}=0.556$. Hence, it can be inferred that, organizational Learning is making a significant impact on knowledge management.

\section{Conclusion}

Knowledge management is an operational philosophy that refers to the process through which an institution collects, organizes, communicates, and analyzes the knowledge in terms of tools, records, and skills. It assists an organization in gaining knowledge and comprehension from its own practice. It is the method from which businesses derive benefit from their intellectual and knowledge-based properties. A knowledge manager is accountable for promoting the continuous phase of knowledge exchange, knowledge renewal, and knowledge development. It is important to consider how information is created and how individuals and organizations acquire the ability to utilize it wisely. All 
benefits from a well-designed information management method. Thus, knowledge management is a relatively modern, inter-disciplinary market model that addresses all facets of expertise within an organization. It incorporates both technical methods and hierarchical routines, as well as information building, in overlapping components. Codification and dissemination of information to foster learning and creativity and, in the process, effect desired organizational change.

As it may not be possible to have the specialist at a place and to avail the benefit of the expertise available with individuals, to bring the best out of the people, to inculcate the innovation in the company culture, for HAL futuristic technology development programs, HAL has employed the Knowledge Management Techniques for managing the knowledge and to gain the organizational learning.

Competitive advantages ultimately rest on an organization's information capabilities, which are impossible to replicate. Organizations the world over utilize information management as a tool to affect systemic improvement. To successfully implement knowledge management activities, organizations must match their policies with their people's current knowledge base and improve knowledge to enable people to efficiently enhance the efficacy of organizational learning and also its efficiency.

\section{References}

[1] Lester Thurow, (1996), Quotes available at https://www.weirdteam.com/Creative-Mind-Quotes.html.

[2] Ronald J Burike, Eddy Ng (2006)- The Changing nature of work and Organizations; Implications for Human Resource Management - HRM Review, PP 86-94.

[3] Dave Ulrich, Bill Schiemann and Libby Sartain (2015), The raise of HR, HR Certification Institute, PP 14.

[4] Nonaka (1991), The Knowledge - Creating Company, Harvard Business Review, November- December 1991, available online from www.hbr.org.
[5] Apelbaum, H and Gallagher, J. (2000), The Competitive advantage of Organizational Learning, Journal of workplace learning, 12 (2), PP 40-56.

[6] Arie De Geus (1988), Planning as Learning, Harvard Business Review, March1998 available online from www.hbr.org.

[7] Brent N. Hunter (2016), The Power of KM; Harnessing the extra-ordinary value of knowledge management, Kindle edition (e-book), Sprint rising production.

[8] Elias M. Awad and Hasan M, Ghaziri (2004), Knowledge Management, Second Edition, Pearson Education pp-64-95.

[9] Argysis, c (1993), Knowledge for Action, Sanfrancisco, Jossey-Bass, 1993.

[10] SirjeVirkus (2014), When does adaptive performance lead to higher task performance? J. Organiz. Behav., 33: 910-924

[11] Chaudhry, Abdus Sattar, Nor Ainah Ali, and Damayanti Iyan Abadi (2008). "Exploiting the Potential of Intranets for Managing Knowledge in Organizations." Journal of Knowledge Management Practice. 9, no. 2, 2008. Available from: http://www.tlainc.com/articl153.html.

[12] www.wikipedia.com/ knowledge management.

[13] Hesketh, B., \& Neal, A. (1999). Technology and performance. In D. R. Ilgen\& D. P. Pulakos (Eds.), The changing nature of performance: Implications for staffing, motivation and development (pp. 21-55). San Francisco: Jossey-Bass.

[14] Cascio, W. F. (2003). Changes in workers, work, and organizations. In: R. J. Klimoski, W. C. Borman \& D. R. Ilgen (Eds), Handbook of psychology (Vol. 12, pp. 401-422). Wiley: Hoboken, NJ.

[15] Moitrayee Das, (2017)- The Importance of agility in work place, Business Manager, September 2017 pp 15-17.

[16] Knowledge Management: Fillings. R. De Jong J and Roefs, CE (2000). Knowledge Management In hrd Office: A comparison of 3 cases, Journal of Workplace Learning, 12 (7)., PP 286-295.

[17] Organizational Learning: Watkins K. E. and Marsick, V. J (1993), Sculpturing the Learning Organizations; Lessons in the art and Science of systematic Change, Jessey- Bass, San Francisco. 